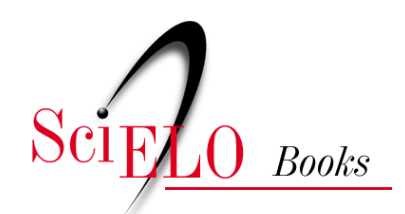

\title{
Os pinhais da fazenda Quatro Irmãos/RS e a Jewish Colonization Association
}

\author{
Isabel Rosa Gritti
}

\section{SciELO Books / SciELO Livros / SciELO Libros}

GRITTI, I.R. Os pinhais da fazenda Quatro Irmãos/RS e a Jewish Colonization Association. In: GERHARDT, M., NODARI, E.S., and MORETTO, S.P., eds. História ambiental e migrações: diálogos [online]. São Leopoldo: Oikos; editora UFFS, 2017, pp. 95-108. ISBN: 978-85-64905-68-9. https://doi.org/10.7476/9788564905689.0007.

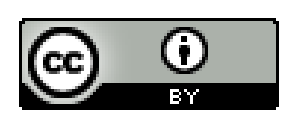

All the contents of this work, except where otherwise noted, is licensed under a Creative Commons Attribution 4.0 International license.

Todo o conteúdo deste trabalho, exceto quando houver ressalva, é publicado sob a licença Creative Commons Atribição $\underline{4.0}$.

Todo el contenido de esta obra, excepto donde se indique lo contrario, está bajo licencia de la licencia $\underline{\text { Creative Commons }}$ Reconocimento 4.0. 


\section{Os pinhais da fazenda Quatro Irmãos/RS e a Jewish Colonization Association ${ }^{1}$}

Isabel Rosa Gritti

\section{Introdução}

Este texto discute a ação da Jewish Colonization Association (ICA) na Fazenda Quatro Irmãos/RS, em relação a sua exploração florestal. A Jewish, enquanto companhia colonizadora, fora criada em 1891 com o objetivo de propiciar a emigração dos judeus vitimas de discriminações no leste europeu. Com este propósito, compra, entre outras, a Fazenda Quatro Irmãos com uma área de 93.985 hectares para assentar os imigrantes. Contudo, a ação da Companhia durante o período de atuação em Quatro Irmãos, isto é, de 1909, ano da compra, até 1962 quando se retira da fazenda, fora dominantemente a de exploração florestal, sem nenhuma preocupação com o reflorestamento.

\section{Uma Mina de Ouro: Os pinhais da Fazenda Quatro Irmãos/RS}

A instalação de imigrantes europeus e/ou seus descendentes como agricultores na Colônia Erechim localizada na região norte do Rio Grande do Sul, teve a presença de dois agentes colonizadores: o Estado e as Companhias Privadas de Imigração e Colonização, neste caso, a Luce e Rosa e a Jewish Colonization Association, mais conhecida como ICA.

A Colônia Erechim, criada pelo Estado em 1908, caracteriza-se pela diversidade étnica e cultural. Aqui estavam indígenas e caboclos. Além deles, foram assentados imigrantes e/ou descendentes de italianos, alemães, poloneses, judeus, russos, austríacos, portugueses entre outros.

\footnotetext{
${ }^{1}$ Este trabalho foi apresentado no $3^{\circ}$ Simpósio Internacional de História Ambiental e Migrações, realizado na UFSC em 2014.
} 
No caso dos imigrantes judeus, sua presença está diretamente ligada a atuação da Jewish Colonization Association. Esta companhia fora criada em 1891 pelo Barão Hirsch, com o propósito de livrar os judeus das perseguições e discriminações de que eram vítimas no leste europeu. Entendia ele que a única maneira de ajudá-los seria a emigração para regiões onde pudessem viver livremente.

À imigração judaica, inserida no contexto das grandes correntes imigratórias e, por conseguinte, provocada pelos mesmos fatores de expulsão (desequilíbrios demográficos e econômicos nos países de origem) e de atração (a procura de trabalho e o sonho de conseguir um pedaço de terra) junta-se um outro elemento, o das discriminações e perseguições de que os judeus eram vítimas, primeiramente, no império russo e, posteriormente, no nazismo europeu (GRITTI, 1997).

Assim é que, no mesmo ano da criação da Jewish, imigrantes judeus oriundos do Leste europeu, mais especificamente do império russo, são assentados na Argentina. Em 1902 a Jewish Colonization Association expande sua área de atuação para o Brasil, particularmente para o Rio Grande do Sul. Neste mesmo ano compra uma área de 5.500 hectares no município de Santa Maria, onde, a partir de 1904, inicia o assentamento de imigrantes judeus.

No ano de 1909, a ICA adquire a Fazenda Quatro Irmãos ${ }^{2}$ com uma área de 93.985 hectares, na época pertencente ao município de Passo Fundo. A ação da ICA na Fazenda se encerra em 1962. Neste período de meio século são assentados apenas 436 imigrantes judeus nos domínios da Jewish em Quatro Irmãos, apesar de seus estatutos a definirem como uma companhia filantrópica, ligada a emigração e assentamento dos judeus.

A atuação da companhia em Quatro Irmãos é constantemente criticada. As críticas mais contundentes dizem respeito ao reduzido número de

\footnotetext{
${ }^{2}$ Como o próprio nome diz, as terras pertenciam a Quatro Irmãos: o coronel David dos Santos, mais tarde Barão dos Campos Gerais, o Dr. José Gaspar dos Santos Lima, juiz de direito da comarca de São Borja e que residiu em Cruz Alta até 1854, Antônio dos Santos Pacheco e Clementino dos Santos Pacheco. Este último residia na fazenda e fora assassinado pelos índios, em 1856. O assassinato teria sido cometido em consequência da insatisfação dos índios, pois "Clementino apossara-se daquela grande extensão de terras, que era patrimônio dos índios, ou pelo menos, considerado como tal, havendo quem diga que ele lhas comprara por irrisória quantia. Um negócio da China" ( Jornal o Erechim de 2 de julho de 1930 ). Arquivo Particular do Sr. Ely Parenti.
} 
imigrantes judeus instalados, críticas estas feitas inclusive pelos lá assentados preocupados com o destino de seus patrícios europeus no período anterior à Segunda Guerra Mundial. O desmatamento da Fazenda Quatro Irmãos também é motivo de preocupação e contestação.

A autorização para que a companhia pudesse atuar no Rio Grande do Sul fora concedida pelo Governo do Estado em 1903 e publicada no jornal $A$ Federação de 20 de julho:

Considerando que a Companhia denominada Jewish Colonization Association, com sede na Inglaterra, organizou-se para promover a imigração de hebreus de vários pontos da Europa e Ásia para diferentes regiões da América; considerando que, de acordo com seus fins institucionais, pretende a mesma Companhia fundar neste Estado núcleos coloniais dedicados aos trabalhos da agricultura, comércio e indústria; considerando, portanto, que os fins da Companhia são de utilidade pública concorrendo para fomentar a imigração e ativar o progresso material; resolvo, na forma do decreto número 434 , de 4 de julho de 1891, artigos 47, 51, 52, 53 e 54 conceder a autorização que solicita o engenheiro Eusébio Lapine, para que possa a dita Companhia funcionar neste Estado (A Federação, 20 jul. 1903).

A colonização de áreas despovoadas era um dos propósitos tanto do Governo Federal quanto dos governos provinciais. Desta forma é que a criação de núcleos coloniais, tanto oficiais, isto é, criados pelo Estado, quanto através de companhias de colonização, tornou-se possível. E a ação da Jewish Colonization Association está inserida no universo das companhias colonizadoras.

No caso específico do Rio Grande do Sul, o povoamento de regiões pouco habitadas e a consequente valorização destas através da criação de toda uma infraestrutura necessária à fixação dos imigrantes dizia respeito ao programa do Partido Republicano Riograndense (PRR), que governou o Estado, ininterruptamente, de 1891 a 1930.

A Jewish Colonization Association foi registrada como uma companhia limitada, em 1891, pelo Barão Hirsch e outros ricos judeus da comunidade de Bruxelas, Londres, Berlim e Frankfurt, com um capital inicial de dois milhões de libras.

O objetivo declarado da associação era assistir e promover a emigração dos judeus de qualquer parte da Europa ou da Ásia e, principalmente, de países em que eles eram submetidos a impostos especiais ou políticos e a outras desvantagens, para qualquer parte do mundo e formar e estabelecer colônias em várias partes do norte e do sul da América e de outros países, 
pela agricultura, comércio e outras atividades. Para realizar estes objetivos, a Jewish Colonization Association estava autorizada a adquirir qualquer território fora da Europa através de governos estaduais, municipais ou autoridades locais, corporações e pessoas (RAKOS, s/d, p. 201).

Também foi dado poder para estabelecer agências de emigração em várias partes do mundo, para construir, alugar, fretar e equipar navios a vapor e outras embarcações, com o propósito de facilitar a emigração.

Quando da morte do Barão Maurice de Hirsch, em 1896, os diretores e administradores da ICA tinham a sua disposição a grandiosa soma de 8.830.116 libras esterlinas, investidas, em sua quase totalidade, em valores e depósitos bancários. Porém, depois de mais de 10 anos de atividade, a companhia dispunha de umas 300.000 libras de ingressos correntes do enorme capital investido em diversas empresas financeiras da Europa. Some-se a isso os enormes bens adquiridos, com o correr do tempo, no Novo Mundo. Comparadas aos ingressos e ao capital com que contavam as outras organizações, tratava-se de somas enormes. El Keren Kavmeth le Israel (Fundo Nacional Judeu), instrumento principal do movimento sionista para a aquisição e o desenvolvimento de terras, informava, em 1905, que, ao final de três anos de atividades, que foram também os anos de apogeu da liderança de Herzel, tinha conseguido coletar de todo o povo judeu apenas a soma de 45.589 libras esterlinas (RAKOS, s/d, p. 203).

Haim Avni diz que o enorme capital próprio da ICA dava aos membros do conselho uma completa independência, e que, no começo de sua atividade, os diretores resolveram não dar ao público informações sobre o capital e os ganhos da companhia, bem como sobre sua decisões. Assim, a opinião pública tinha muito pouca influência sobre as decisões da ICA, o que não acontecia com as demais instituições de amparo aos emigrantes israelitas. Da mesma forma, a campanha que a imprensa judia do leste europeu e de outras regiões desenvolveu contra essa atitude da ICA não mereceu, por parte dela, em sua maioria, reação pública.

Após a morte do Barão de Hirsch, um novo conselho foi eleito. Este era composto por S. H. Goldschmidt, Narcise Leven, Salomão Reinach, Alfred L. Cohen, Herbert Lousada, Chief Rabbi Zadockahn, Claude J. G. Montefiori, Leopold Schioss, Julius Plotke, Dr. Edmund Lachmann e Franz Philipson.

Para Jeffrey Lesser o novo conselho da Jewish Colonization Association possuía muito pouco do espírito bondoso do Barão. Em 1900, eles decidi- 
ram "expandir o alcance da organização, sempre com a ideia de que uma coincidência de interesses poderia ser estabelecida entre benevolência e capitalismo" (LESSER, 1989, p. 27). O Canadá foi uma das mais novas nações escolhidas pela colonizadora judaica. E, em 1901, a ICA enviou seu diretor argentino David Cazés e Eusébio Lapine, engenheiro agrônomo e administrador-chefe da colônia argentina de Entre Rios, para estudarem as condições de expansão no sul do Brasil. As informações que eles colheram foram boas e a "Companhia decidiu que o Rio Grande do Sul, devido à sua proximidade com as colônias argentinas, à sua religião tolerante, comandada constitucionalmente, e ao seu desejo por novos imigrantes, seria um bom lar para os judeus russos" (LESSER, 1989, p. 25).

A Jewish Colonization Association inicia sua longa trajetória de atividades no Brasil e, mais, especificamente, no Rio Grande do Sul, no ano de 1902. Nesse ano, a ICA comprou sua primeira propriedade no estado, em Pinhal, no município de Santa Maria.

Esse primeiro núcleo judaico no Rio Grande do Sul foi denominado de Filipson, em homenagem ao então vice-presidente da ICA e presidente da Compagnie Auxiliaire de Chemins du Fer au Brésil, empresa belga arrendatária, na época, da rede da Viação Férrea do Rio Grande do Sul.

Em 1904, a ICA dá início a sua atividade de colonização. Inicialmente, instala, em Filipson, 37 famílias judias, num total de 267 pessoas vindas da Bessarábia, em lotes de 25 hectares de terra de mato e campo. Além disso, quando de sua chegada, os imigrantes receberam uma casa para moradia, instrumentos de trabalho agrícola, duas juntas de bois, duas vacas, um cavalo e, enquanto não pudessem viver do produto das colheitas, a ICA lhes dava um suprimento em dinheiro, variável de acordo com o número de pessoas da família.

O fato de a colônia Filipson estar instalada nas proximidades da estrada de ferro administrada por Franz Philipson, pareceu a Lassance $\mathrm{Cu}$ nha um elemento importante para a sua prosperidade, pois que, "sem dúvida, será motivo para que se interesse pela prosperidade desta e de outras colônias que estabelecer, pelos resultados pecuniários que delas advirão no transporte de produtos coloniais pela estrada de ferro" (CUNHA, 1908, p. 254).

Contudo, a tão esperada e propalada prosperidade da colônia Filipson não aconteceu, o que não impediu que a ICA adquirisse novas áreas no 
estado e, não acidentalmente, nas proximidades da linha férrea. Assim, quando, em 1909, a Jewish Colonization Association compra a Fazenda Quatro Irmãos, onde pretende criar um novo núcleo israelita, a colônia Filipson encontra-se praticamente despovoada.

A localização da nova área adquirida pela ICA no estado é similar à colônia Filipson. Ela encontra-se nas proximidades da linha férrea São Paulo-Rio Grande, ainda em construção pela Compagnie Auxiliaire de Chemins du Fer au Brésil.

Se, por um lado, o governo do estado viu, na ação da Jewish, a possibilidade de concretizar alguns de seus objetivos, como o de povoar as regiões pouco povoadas, através da imigração, por outro lado, podemos constatar uma afinidade de interesses entre a ICA e a Compagnie Auxiliaire de Chemins du Fer.

Como toda companhia colonizadora, a ICA, "antes de receber os imigrantes, prepara-lhes os lotes coloniais construindo moradias, hortas, roças, etc. de modo a facilitar-lhe o trabalho no período inicial de adaptação e mediante inventários, fornece-lhes ferramentas agrícolas, animais e tudo o mais que é necessário para a agricultura. Isto feito, a Associação lavra com os colonos contratos de Promessa de Compra e Venda sobre os lotes por eles ocupados" (BACK, 1958, p. 275). 
Figura 1: Mapa de Quatro Irmãos

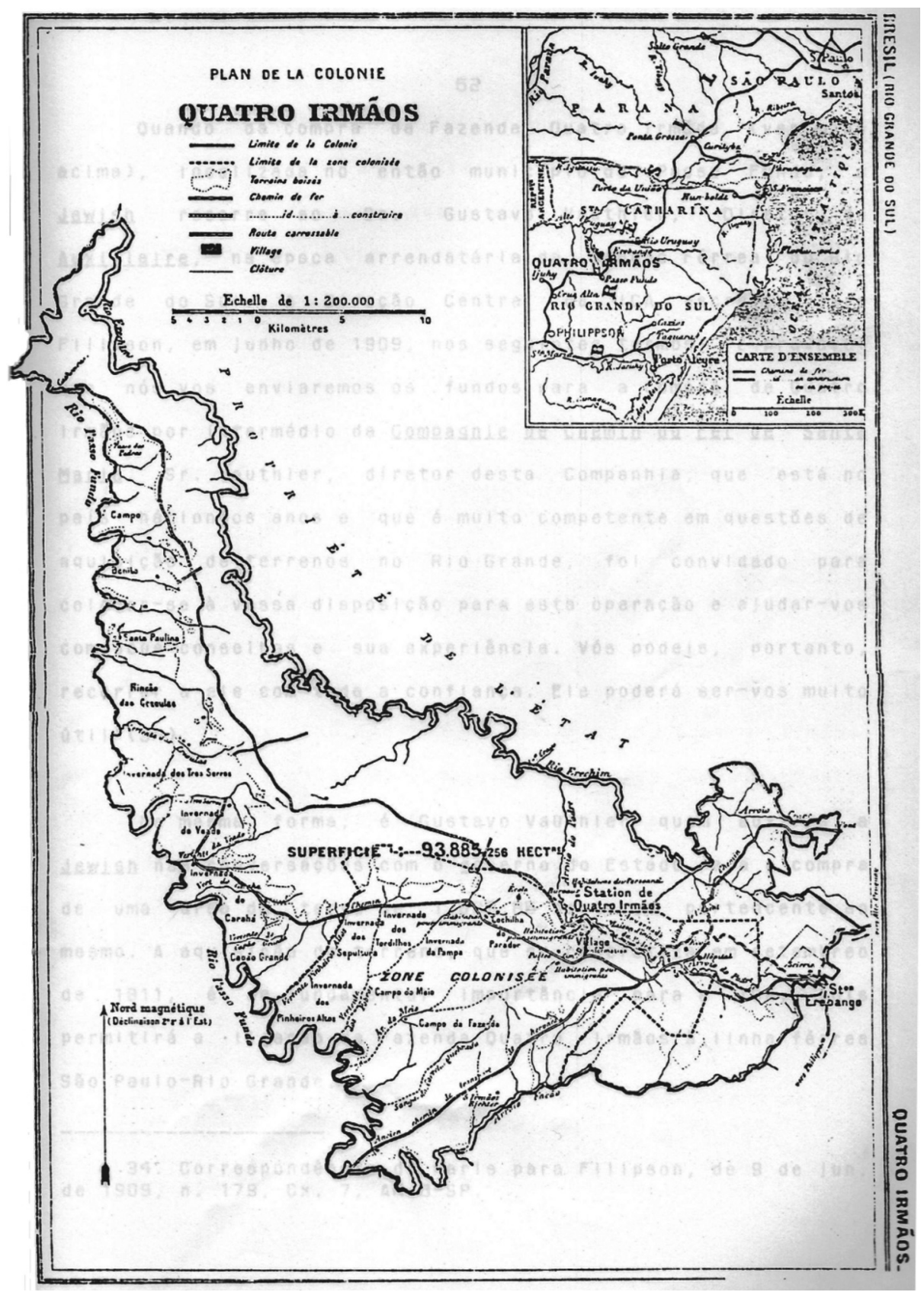

Fonte: acervo da autora 


\section{A riqueza florestal da Fazenda Quatro Irmãos}

O interesse da ICA pelas florestas de Quatro Irmãos não era recente. A avaliação das florestas e a viabilização de sua exploração são anteriores à atividade de colonização israelita, ocorrida a partir de 1912.

Seis meses após a compra do domínio, isto é, em janeiro de 1910, a direção central da Jewish comunicava através de correspondência ao diretor da Colônia Filipson "a visita próxima de um enviado especial do Sr.Teixeira Soares para estudar a questão da floresta em nossa propriedade, com a finalidade de vos apresentar um relatório detalhado sobre o valor da mesma" (Correspondência da ICA, 10 jun. 1910).

É significativo o fato de que, no ano de 1911, foram feitas, por diferentes pessoas, quatro avaliações das florestas existentes no domínio recentemente adquirido pela Jewish. Dentre as avaliações realizadas neste ano, citamos a opinião do engenheiro florestal da Bromberg e Cia. de Porto Alegre: "Este senhor ficou maravilhado e me fez grandes elogios à qualidade das madeiras. Expressou-me sua autorizada opinião de que nossa sociedade não deveria ainda empreender a exploração das madeiras, alegando que esta indústria não terá seu verdadeiro valor a não ser dentro de alguns anos" (Correspondência da ICA, 5 de jan. 1911).

A importância atribuída pela ICA à riqueza florestal de seu domínio de Quatro Irmãos pode ser confirmada pelo fato de que é o diretor-geral da companhia que vem para o Rio Grande do Sul, em 1911, colher informações em relação ao mercado madeireiro. Em julho de 1911, o diretor da colônia Filipson escrevia para a direção central em Londres: "Acompanhando o Sr. Oungre, em diferentes centros, como Porto Alegre, Rio Grande, Pelotas, Rivera, ocupei-me de colher informações sobre o comércio de madeira. O Sr. Oungre pôde constatar, por toda parte, um grande entusiasmo por esta indústria, sobretudo no dia em que todas as informações forem reunidas para poder exportar a madeira para a República Argentina e Uruguai" (Correspondência da ICA, 6 jul. 1911).

A riqueza florestal existente na mais nova propriedade da Jewish Colonization Association é por demais evidente no entusiasmo do diretor da colônia Filipson. Em 6 de fevereiro de 1911, Leibovich exclamava: "Os cálculos a respeito do valor da madeira provam suficientemente as grandes riquezas que há por explorar, e eu não saberia fazer melhor comparação do que chamando-as de mina de ouro" (Correspondência ICA, 6 fev. 1911). 
A preocupação por parte da ICA com a exploração das florestas existentes nos 93.985 hectares da Fazenda Quatro Irmãos é constante. Em 1915, quando o Sr. Forbes planejava vir ao Brasil para avaliar os domínios da Brazil Railway, a direção central da ICA pedia para que a administração de Quatro Irmãos ficasse atenta à forma pela qual esta empresa pretendia explorar o seu domínio de Três Barras. Da mesma forma, pedia para que o diretor de Quatro Irmãos ficasse atento ás notícias referentes à navegabilidade do Rio Uruguai, porque "esta questão representa o mais alto interesse para o desenvolvimento do comércio de nossas colônias" (Correspondência da ICA, 4 mar. 1915).

Como consequência do interesse pela exploração florestal, a ICA toma o cuidado de incluir, nos contratos de promessa de compra e venda realizados com os colonos israelitas, uma cláusula proibindo-os de desmatar o lote adquirido, sem a prévia autorização da companhia. Da mesma forma, os terrenos só eram vendidos aos não israelitas após a ICA ter extraído a madeira dos respectivos lotes, através de um contrato de exploração florestal, em que a companhia arrendava uma determinada área arborizada aos madeireiros, israelitas ou não, para que a explorassem.

A exploração florestal na Fazenda Quatro Irmãos é intensificada com a Primeira Grande Guerra, período favorável à indústria madeireira, uma vez que, nesta época, não sofria a concorrência dos produtores europeus, exportando, assim, para os países vizinhos, a Argentina e o Uruguai.

A construção do ramal férreo Quatro Irmãos - Erebango, numa extensão de dezenove quilômetros, está diretamente ligada à exploração florestal, principal atividade desenvolvida pela ICA em seu domínio de Quatro Irmãos. Este ramal ligaria a sede da fazenda à linha da Viação Férrea do Rio Grande do Sul.

Já em 1911, a construção do ramal férreo estava definida. A riqueza florestal da fazenda foi o fator determinante para a sua construção, uma vez que a exploração das florestas só seria possível com a existência de um meio de transporte que ligasse a fazenda à Rede da Viação Férrea do Rio Grande do Sul.

Além da preocupação com a segurança dos 93.985 hectares da fazenda constantemente ocupada por colonos em busca de terras, a ICA enfrentou sérias denúncias em relação ao desmatamento por ela realizado.

Em 1951, o representante do Partido Trabalhista de Vila Campinas, Distrito de Quatro Irmãos, em correspondência ao governador do Estado 
Ernesto Dornelles, acusa a Jewish Colonization Association de estar desmatando indiscriminadamente e não aproveitando de forma integral o pinheiro abatido.

A denúncia apresentada ao governador do Estado é contestada pelo Delegado Florestal do Rio Grande do Sul, Henrique Luiz Roessler, que diz ser "lamentável que mais uma vez a ICA esteja sendo molestada com expediente desta natureza, quando é sabido que é uma das poucas que cumprem as suas obrigações com o Serviço Florestal" (Ofício n. 3.689, 30 jun. 1951).

A Jewish toma conhecimento da denúncia feita contra ela pelo Delegado Florestal Henrique Luiz Roeesler que, além da cópia da denúncia entregue ao governador, envia para a administração de Quatro Irmãos a resposta ao pedido de informações que apresentará ao governador do Estado. "Estou passando estas cópias às vossas mãos em caráter confidencial para que examineis os motivos da denúncia e providências cabíveis, sem represálias, unicamente para fins preventivos" (Ofício n. 3.689, 30 jun. 1951).

Em resposta ao pedido de informações solicitado pelo governador do Estado, Henrique Luiz Roessler diz que a Jewish Colonization Association tem sido constantemente denunciada ao poder público como destruidora dos pinhais de sua propriedade e argumenta que a

\begin{abstract}
empresa requereu, regular e anualmente, ao Serviço Florestal, licenças para derrubar os pinheiros de sua exploração, tendo inicialmente reflorestado com eucaliptos, na proporção exigida, fazendo ainda experiências com essências nobres e pinheiros, passando, desde 1948, a plantar essencialmente o pinheiro, na proporção de 5 mudas para cada árvore abatida acima de $40 \mathrm{~cm}$ de diâmetro. A ICA está perfeitamente enquadrada nos dispositivos do Código Florestal, estando as suas obrigações de reflorestamento em dia, conforme foi verificado pessoalmente pelo signatário deste em diversas diligências de vistorias procedidas na Fazenda Quatro Irmãos (Ofício n. 3.688, 15 jun. 1951).
\end{abstract}

O Delegado Florestal Henrique L. Roessler encerra a resposta dada ao governador dizendo: "Em compensação à devastação observada nos pinhais nativos da ICA, seria interessante o denunciante fazer uma visita também ás áreas de reflorestamento da empresa, onde várias centenas de milhares de pinheiros novos provam o zelo dos seus dirigentes pela perpetuação da essência nas terras da sua propriedade, não negociáveis em lotes" (Ofício n. 3.688, 15 jun. 1951).

Apesar de o delegado florestal afirmar que a ICA repovoava as áreas desmatadas com o plantio de novas árvores e que passara, "desde 1948, a 
plantar essencialmente o pinheiro", os resultados do reflorestamento, observados em 1959, diferem totalmente do apregoado. O diretor de Quatro Irmãos avalia o resultado do reflorestamento, em substituição aos pinheiros abatidos:

Como resultado do reflorestamento, temos atualmente uma área de aproximadamente 200 hectares com plantio de eucaliptos, cuja idade varia entre um e dez anos. Esta área de terra está incluída nas nossas reservas. Infelizmente, esse eucaliptal não tem valor comercial maior do que se fosse apenas considerado o valor da terra. Este plantio de eucaliptos foi uma consequência do compromisso de reflorestamento a que estávamos sujeitos por lei (Correspondência n. 1.524, 23 maio 1959).

A relação bastante "próxima" da ICA com o Delegado Florestal do Rio Grande do Sul, evidente no caso acima relatado, pode ser novamente confirmada, quando anula o ato do delegado florestal de Erechim que indeferiu em 1949 , um pedido de desmatamento de 11.350 pés de pinheiro feito pela Jewish.

Em 1949, o delegado florestal de Erechim, Antônio Pereira de Souza indefere um pedido da Jewish Colonization Association para derrubar 11.350 pés de pinheiro. Antônio Pereira de Souza alegava que a solicitante estava na obrigação de reflorestamento de 153.706 pés de pinheiros, e as matas de propriedade da requerente estão condicionadas à cláusula restritiva do art.15 do referido código, tendo-se em vista a constituição de reserva florestal, declarada de utilidade pública pelo Decreto Estadual número 658, de 10 de março do ano em curso (A VOZ DA SERRA, 20 maio 1949).

Interessante destacar que, apesar de tornar sem efeito o indeferimento determinado pelo delegado florestal de Erechim, Antônio Pereira de Souza, em relação ao pedido da ICA de cortar 11.350 pés de pinheiro em 1949, Henrique Luiz Roeesler reconhece, no ano seguinte, o trabalho do delegado florestal de Erechim, inclusive lembrando sua atuação em defesa do reflorestamento na Fazenda Quatro Irmãos, além de considerá-lo como o melhor delegado florestal. É o que ele declara no atestado expedido em São Leopoldo em 4 de abril de 1950. Roeesler, escreve:

Atesto, em razão do meu cargo, que o Sr. Antônio Pereira de Souza, desde o ano de 1942, vem exercendo as funções de Delegado Florestal com rara inteligência e capacidade, energia e imparcialidade, atuando sempre com serenidade e equilíbrio e impondo o respeito ao Serviço Florestal em toda zona nordeste do Estado, cujo centro é Erechim, sede de sua delegacia. Intransigente protetor das nossas florestas e apaixonado fomentador do reflorestamento, conseguiu criar uma nova mentalidade florestal entre os madei- 
reiros de sua zona. À sua iniciativa cabe a campanha contra a exploração ilegal das florestas dos redutos indígenas deste Estado e das do patrimônio público, assim como a repressão contra a devastação sem reflorestamento dos extensos pinheirais da Empresa Colonizadora Jewish Colonization Association e tantos outros de relevância. Encarregado da fiscalização da caça e da pesca, conseguiu disciplinar e moralizar esses esportes, impedindo a continuação da destruição da fauna na vasta região sob a jurisdição. Como organizador tem demonstrado qualidades invulgares, sendo considerado por nós como o nosso melhor delegado (Atestado, 4 abr. 1950).

A situação em que se encontrava Quatro Irmãos, após meio século de atuação da ICA, confirma que o interesse da companhia foi prioritariamente econômico, dedicando-se à exploração florestal e à venda de terrenos, o que não se apropria aos princípios e objetivos de uma companhia colonizadora, que se intitulava filantrópica e preocupada com a sorte de seus irmãos israelitas.

Apoiando o pedido da Legião da Boa Vontade, que solicitava à Jewish Colonization Association a doação de um prédio e de uma pequena área de terra para instalação, em Quatro Irmãos, de um estabelecimento de recuperação de menores, o diretor da ICA em Quatro Irmãos argumentava, em abril de 1962:

À mercê de um pugilo de homens despreendidos e abnegados, a nossa Associação, colaborando nessa ideia, estaria concluindo com chave de ouro as suas atividades de longos anos em Quatro Irmãos. Apesar de nossa inglória tarefa de colonização, é lamentável e inegável que o povoado de Quatro Irmãos, depois que foram concluídas as atividades de exploração de pinheiros que existiam em nossa Fazenda, tornou-se uma vila de atividade inexpressiva e um aglomerado de gente humilde e sem trabalho, onde impera a absoluta miséria. Uma infância abandonada e faminta prolifera nas ruas semidesertas do povoado. Os adultos vivem de pequenos expedientes, sem encontrar trabalho fixo. Quatro Irmãos não é hoje nem sombra daquele povoado promissor de 8 ou 10 anos atrás, quando as atividades extrativas de madeira proporcionavam trabalho a dezenas de famílias. Não deixa, pois, de ser elogiável e, sobre todos os pontos de vista, digna, essa idealização de amparo aos mais desprotegidos da sorte (Correspondência da ICA, 16 abr. 1962).

\section{Considerações finais}

Podemos concluir que a Jewish Colonization Association preocupou-se e ocupou-se primeiramente com as condições adequadas à exploração da riqueza florestal da fazenda e, só num segundo momento, com a instalação 
dos imigrantes israelitas. Estes tiveram participação decisiva na valorização dos 93.985 hectares da Fazenda Quatro Irmãos, através do povoamento e do consequente trabalho por eles desenvolvido na fazenda, incluindose a construção do ramal férreo.

\section{Referências e fontes}

ATESTADO de 04 de abril de 1950, do Ministério da Agricultura - Serviço Florestal Delegacia Regional do RS, em São Leopoldo, para Antônio Pereira de Souza. Arquivo Particular Antônio Pereira de Souza.

AVNI, Haim. Argentina y la Historia de la immigración judia (1810-1950). Buenos Aires: Editorial Universitaria Magnes, 1983.

BACK, Leon. Imigração judaica no Rio Grande do Sul. In: BECKER, Klaus (Org.). Enciclopédia Rio-Grandense. v. 5. Canoas: Ed. Regional,1958.

CORRESPONDÊNCIA da Jewish Colonization Association (ICA), de Filipson para Paris, 10 junho de 1910, n. 235. Pesquisas Regionais, Erechim, n. 7, ano 5, nov. 1982.

CORRESPONDÊNCIA da Jewish Colonization Association (ICA), de Filipson para Paris, 5 de janeiro 1911, n. 263. Pesquisas Regionais, Erechim, n. 7, ano 5, nov. 1982. Correspondência da Jewish Colonization Association (ICA), de Filipson para Paris, 6 de fevereiro de 1911, n. 268. Pesquisas Regionais, Erechim, n. 5, ano 7, jul. 1985.

CORRESPONDÊNCIA da Jewish Colonization Association (ICA), de Filipson para Paris, 6 de julho de 1911, n. 283. Pesquisas Regionais, Erechim, n.15, ano 7, jul. 1985.

CORRESPONDÊNCIA da Jewish Colonization Association (ICA), de Quatro Irmãos para Londres, 16 de abril de 1962, n. 1777, cx. 19, m. 2. AHJB-SP.

CORRESPONDÊNCIA da Jewish Colonization Association (ICA), de Quatro Irmãos para Londres, 16 de abril de 1962, n. 1777, cx. 19, m. 2. AHJB-SP.

CORRESPONDÊNCIA da Jewish Colonization Association (ICA), de Paris para Quatro Irmãos, 4 de março de 1915, n. 418, cx. 8, m. 1. AHJB-SP.

CORRESPONDÊNCIA n. 1.524, de 23 de maio de 1959, de Quatro Irmãos para Paris, cx. 19, m, 4. AHJB-SP.

CUNHA, Ernesto Antonio Lassance. O Rio Grande do Sul: contribuição para o estudo de suas condições econômias. Rio de Janeiro: Imprensa Naional, 1908.

GRITTI, Isabel R. Imigração Judaica no Rio Grande do Sul: A Jewish Colonization Association e a colonização de Quatro Irmãos. Porto Alegre: Martins Livreiro Editor, 1997. 
GRITTI, Isabel R. O Reflorestamento na Fazenda Quatro Irmãos. Perspectiva, Erechim, ano 20, n. 80, p. 111-118, dez. 1998.

JORNAL A VOZ DA SERRA, Erechim, 20 maio 1949.

LESSER, Jeffrey H. Pawns of the powerful: jewish immigration to Brazil, 1904-1945. Tese (Doutorado em História), New York City, New York University, 1989.

OFÍCIO n. 3.688, de 15 de junho de 1951, do Delegado Florestal do RS, Henrique L. Roessler, ao Ilmo Sr. Dr. Diretor de Terras e Colonização da Secretaria da Agricultura, Porto Alegre, cx. 17, m. 3. AHJB-SP.

OFíCIO n. 3.689, de 30 de junho de 1951, do Ministério da Agricultura - Serviço Florestal de São Leopoldo, RS, ao Sr. Herbert Schall, da Administração da ICA em Quatro Irmãos, cx. 17, m. 3. AHJB-SP.

RAKOS, Kennee S. Baron de Hirsch, the Jewish Colonization Association and Canada. (Documento sem informações, existente na biblioteca do Instituto Cultural Judaio Mar Hagall de Porto Alegre, s/d). 